\title{
The Function AnALYSIS ON the EstABLISHMENT OF MARKET-ASSISTED MECHANISMS-TAKING THE CHAMBER OF COMMERCE AS AN EXAMPLE
}

\author{
Xu Meng ${ }^{1^{*}}$ \\ ${ }^{1}$ College of Economics and Management, Shangqiu Normal University, Shangqiu, 476000, P.R.China, \\ xumeng-sq@126.com, tel.: +8615896981851
}

\begin{abstract}
It is necessary to solve the subsistent problem of excessive transaction costs in China's economic restructuring reform and establishment of market economic system through establishing a marketassisted mechanism. And the chamber of commerce organizations can provide a sort of mechanism to reduce transaction costs. Several problems need to be considered when we bring the market-assisted mechanism into play, such as perfecting the legitimacy and self-discipline of the chamber of commerce, taking measures against the anti-dumping in the context of WTO, developing international economic and technological cooperation and exchanges, paying attention to structuring the exchange platform of industry-university-research, etc.
\end{abstract}

\section{Key Words}

Market-Assisted Mechanism; the Chamber of Commerce; Game Theory

\section{JEL Classification}

LO

DOI: https://doi.org/10.14311/bit.2018.01.03

Editorial information: journal Business \& IT, ISSN 2570-7434, CreativeCommons license (c) (1) published by CTU in Prague, 2018, http://bit.fsv.cvut.cz/ 


\section{Background on the Adjustment and Reform of China's Market Economic System Formation}

China was plagued by several factors on establishing the economic system during the early years of the new nation, like the incomplete theoretical system of socialist economic system, the influence of Stalin Model which simplified the economic issues, and the huge population stress and weak industrial foundation, the grim international situation that made China have few ways to communicate with western countries, etc. All these factors forced China to centralize the resource elements through a planned and develop various national industries step by step based on the consideration of national security and development. However, in the practice of planned economy, it was absolutely impossible for government to negotiate with every enterprise because of the high transaction costs. Due to this factor, we must establish a unified top-down management system. On one hand, our nation became the owner of the vast majority of enterprises through redemption. On the other hand, government should set up National Planning Commission and integrated economic and professional management departments. The Planning Commission shall calculate and formulate a unified plan on national economic management and resource distribution and then carry it out hierarchically through professional ministries and commissions and their local corresponding subordinate departments at all levels. Yet this kind of approach similar to the "unified utility function" on managing enterprises will inevitably ignore the initiative of the enterprise itself. In addition, due to the long-term financial and personnel control, enterprises will gradually become accessories of the governmental departments, and at the same time, government agencies will expand, which will finally lead to the "politicization of economic life". Therefore, we can say that this approach has side effects on both economy and politics.

In order to solve the problems arising from the systems above, China has adopted a series of adjustments and reforms putting the economic theory into practice. It started from the On the Ten Relationships and the "administrative decentralization" in the 8th Third Plenary Session of the Central Committee of CPC. And then, in 1978, the government formally decided to reform. In the 14th NPC of the PRC, the goal of the socialist market economy reform was announced and in the 14th Third Plenary Session of the Central Committee of CPC, the government clearly announced to establish a modern enterprise system that meets the requirements of the market economy. Finally, until the policy of invigorating large enterprises and relaxing control over small ones and implementing a strategic reorganization of state-owned enterprises in the 15th NPC of the PRC, the macroeconomic system and the micro-subject norm of China's market economy has been basically formed. In the current market economy system, due to the small amount of capital and the scattered number of individual enterprises in China, coupled with the liberalization of corporate autonomy since the reform and the demolition of a number of related ministries and commissions, we are facing the problem of excessive transaction costs in exchanges between government and enterprises, and among enterprises. On the one hand, from the perspective of the relationship between the government and the market and the realization of latecomer advantages, our government cannot give up its guidance to enterprises; on the other hand, the strength of our own enterprises is still insufficient to participate in international market competition. And to achieve their own competitive advantages, they need to strengthen their contract with the government and the cooperation with the same industry and upstream and downstream industries. The policy of invigorating large enterprises and relaxing control over small ones that the government communicates with a small number of large enterprises rather than all enterprises is, in itself, a method of reducing negotiation costs in economic regulation and control. However, the problem of transaction costs in all markets cannot be effectively solved by just relying on this method. We need to establish the supporting mechanisms that will help to make the market system a better one in all aspects to lubricate the exchanges and interactions between the government and enterprises, and among enterprises. In the following, we use the organization mechanism of the chamber of 
commerce as an example to illustrate how establishment of an auxiliary market mechanism reduces the search, negotiation, and supervision of implementation costs in transactions.

\section{The function Analysis of Chamber of Commerce Organization in Market economy}

In the following game of "Reputation Model", we assume that there are two manufacturers 1 and 2 in the market, and the government provides some guidance to the industry. If manufacturers 1 and 2 are implemented according to the government's guidance, the cost for both is $C_{i}$, The gain is $B_{i}(i=1,2)$. If only one party performs the government's guidance, then the other party can take his ride and get a net return of $\mathrm{Bi}$, and the executing company will pay a double cost $2 \mathrm{C}_{\mathrm{i}}$, (assume that $0<\mathrm{C}_{\mathrm{i}}<\mathrm{B}_{\mathrm{i}}<2 \mathrm{C}_{\mathrm{i}}$, to ensure that $0<B_{i}-C_{i}<B_{i}$ and $\left.B_{i}-2 C_{i}<0\right)$. The two sides repeat the game for $n$ times, and the specific payment function is expressed as follows.

Table 1. Reputation Game Model of two manufacturers.

\begin{tabular}{|l|l|l|l|}
\hline \multicolumn{2}{|c|}{} & \multicolumn{2}{|l|}{ Manufacturer 1} \\
\cline { 3 - 4 } & Execute & Do not execute \\
\hline \multirow{2}{*}{ Manufacturer 2 } & Execute & $\left(B_{i}-C_{i}, B_{i}-C_{i}\right)$ & $\left(B_{i}-2 C_{i}, B_{i}\right)$ \\
\cline { 2 - 4 } & Do not execute & $\left(B_{i}, B_{i}-2 C_{i}\right)$ & $(0,0)$ \\
\hline
\end{tabular}

Another hypothesis is that both firms 1 and 2 have the possibility of $p(0<p<1)$ to be "irrational" cooperative participants and the possibility of 1-p to be "rational" non-cooperative participants. The non-cooperative participants maximize their own payment in each game according to the existing information (Every time the static game equilibrium is "do not execute, do not execute") while the cooperative participants choose the "cold strategy", and firstly select "execute" until the other party takes the "do not execute" strategy for the first time, and then after that choose "do not execute". In order to simplify the calculation, we assume that $\mathrm{B}_{1}=\mathrm{B}_{2}=\mathrm{B}, \mathrm{C}_{1}=\mathrm{C}_{2}=\mathrm{C}^{1}$, and $\delta$ is the time discount factor, $0<\delta<1$.

Take manufacturer 1 as an example:

In the first stage, if the manufacturer 1 chooses not to cooperate, its expected payment is:

$$
p B+(1-p) \times 0=p B
$$

if the manufacturer 1 chooses to cooperate, its expected payment is:

$$
\begin{aligned}
(1-p)(B-2 C)+p[(B-C)+\delta(B-C) & \left.+\delta^{2}(B-C)+\delta^{3}(B-C)+\ldots \delta^{n-1}(B-C)\right] \\
& =(1-p)(B-2 C)+p(B-C)\left(1-\delta_{n}\right) /(1-\delta)
\end{aligned}
$$

Manufacturer 2 can be seen by the same reasoning of symmetry.

To enable the manufacturer 1 to choose the cooperation strategy from the beginning, it is necessary to satisfy the following incentive compatibility constraints which is:

$$
p B<(1-p)(B-2 C)+p(B-C)\left(1-\delta_{n}\right) /(1-\delta)
$$

\footnotetext{
${ }^{1}$ In order to simplify the calculation of the model, this paper adopts the "prisoner's dilemma" approach. Of course, because the $\mathrm{Bi}$ and $\mathrm{Ci}$ of each manufacturer are very likely to be different in reality, the outcome of the game is probably the form of "intelligent pig game", and this article will be discussed later in this article.
} 
And the solution is

$$
\mathrm{n}>\mathrm{n}_{1}=\log _{\delta} \frac{p(B-C)-(1-\delta)[p B-(1-p)(B-2 C)]}{P(B-C)}
$$

That is, if the number of game repetitions reaches $\mathrm{n} 1$ or more, the game will have a "Cooperation Stage" of a certain length (n0). Both parties choose to adopt a cooperative strategy and jointly implement the government's useful guidance ${ }^{2}$.

The game process above is based on the condition that two companies make decisions independently. Next, there is an introduction about a related game model ${ }^{3}$ of the model above. We call it "Commercial Game". Since manufacturers 1 and 2 are in the same market, it is possible for the two parties to strengthen communication through the chamber of commerce. We assume that the cost for both parties in joining the chamber of commerce is $C_{m}$ and the profit is $B_{m}$. The chamber of commerce requires all member companies to act in unison. Therefore, in the game of the chamber of commerce, the profits from the company's exit will be the savings of the current membership fee $\mathrm{Cm}$, and the sum of the revenues remaining in the chamber of commerce will be $\left(B_{m}-C_{m}\right) \times\left(1-\delta_{n}\right) /(1-\delta)$. And then, there are incentive compatibility constraints to participate in the chamber of commerce game. That is

$$
C_{m}<\left(B_{m}-C_{m}\right) \times\left(1-\delta_{n}\right) /(1-\delta)
$$

Note: Here, $\mathrm{Bm}$ and $\mathrm{Cm}$ should be equal (or have little difference) for each vendor. We assume that in each activity of the chamber of commerce, the government only implements a guidance plan so that the two related games have simultaneity. To connect two games and obtain new cooperation, the incentive compatibility constraints required to meet

$$
p B+C_{m}<(1-p)(B-2 C)+p(B-C)\left(1-\delta_{n}\right) /(1-\delta)+\left(B_{m}-C_{m}\right) \times\left(1-\delta_{n}\right) /(1-\delta)
$$

And the solution is

$$
\mathrm{n}>\mathrm{n} 2=\log \delta \frac{\left(B_{m}-2 C_{m}-p B+B-2 C+p C\right)+\delta\left(2 p B-B+2 C-2 p C+C_{m}\right)}{p B-p C+B_{m}-C_{m}}
$$

Through comparing $\mathrm{n}_{1}$ with $\mathrm{n}_{2}$, we can know that the next type should be satisfied,

$$
\frac{B_{m}-C_{m}}{C_{m}}>\frac{2 p B-B+2 C-2 p C}{p(B-C)}
$$

We can get $\mathrm{n}_{2}<\mathrm{n}_{1}$

From this we can conclude that the introduction of the association related game can widen the value range of $n$. Even if the constraint $n>n_{1}$ of the first reputation model cannot be satisfied, the enterprise still can achieve cooperation through $n>n_{2}$ as long as the value of the chamber of commerce game can meet the requirement of (8). Therefore, the links between companies can be strengthened through the chamber of commerce. Apparently, the greater the value of $B_{m}$ is, the easier it is to meet the conditions of (8). In addition, the better the cooperation between companies as well as enterprises and government guidance is, the more likely $B_{m}$ may increase.

Back to the real economy, let us first briefly examine the case of the Wenzhou smoking accessories association that everyone is familiar with. In December 2003, the European Union finally abolished the

\footnotetext{
${ }^{2}$ Of course, there will still be non-cooperative stage $n-n_{0}$, but it is not related to the content of this paper.

${ }^{3}$ The theory and method of linked game analysis is from the part about the model of irrigation game and community game in Comparative Institutional Analysis written by Aoki Masahiko, translated by Zhou Lian, published by Shanghai Far East Press in 2001.
} 
CR regulations, and Chinese lighter industry represented by Wenzhou achieved victory. Huang Fajing, vice president of the association, has become the first person to deal with international trade barriers, and was elected the 2003 CCTV China economic year figure.

In reviewing this case, we can at least find the following problems. First, the "Lighter Safety Standard" was promulgated in the United States in 1993 (Lighter manufacturers lost the US market because of this). The European Union only copied the United States and disclosed the draft in 1998. Huang Fajing did not hear of this news until October 2, 2001. After hearing this news, he, together with the officials of the Ministry of Commerce's Fair Bureau, went to Europe in March 2002 to negotiate. This shows that we lack of anti-dumping warning systems, market information from abroad, and the adequacy of joint corporate operations. Second, news reports on this deed have been sensationally written. "After more than two years of training, Huang Fajing has already been very familiar with the "Technical Barriers to Trade Agreement". Many other industry associations often invited him to lecture on how private enterprises have dealt with trade barriers. In this regard, Huang Fajing joked that he had become a doctor after a long-term illness." In fact, at home, it is incumbent for the foreign trade disciplines in Chinese universities and government agencies to popularize international trade knowledge and professional training among foreign companies. If our entrepreneurs must have a longterm illness to become good doctors, then the cost on our economic development and social progress will be too high. How to establish a good institutional platform to realize the cooperation among industries universities, and research institutes should become an important issue in the development of chambers of commerce. Third, in the review of Mr. Huang Fajing, he specifically mentioned the support and help offered by his European trading partner, Klaus, chairman of the European Lighter Importer Association. This can be seen as the reminiscent of the "united front". Only by maximizing our interest alliances, can we minimize our opponents at the same time and take the initiative.

\section{Problems in the functioning of Chamber of Commerce organizations and recommendations}

First, improve the legitimacy and self-discipline of the Chamber of Commerce. ${ }^{4}$

The members of China's industrial industry associations generally do not exceed $40 \%$ of the total number of enterprises in the whole industry. They are, in fact, lacking sufficient legitimacy and representativeness. Some trade associations changed from the original administrative companies and are still basically controlled by a few large-scale enterprises, with the efficiency of office work left to be improved. In the aforementioned model, the $\mathrm{Bm}$ and $\mathrm{Cm}$ among the members of the chambers of commerce are seriously unequal, which may change the nature of the game among the companies that used to be the "Prisoner's Dilemma" into a "Boxed Pig Game" or increase the asymmetry of the participants in the "Boxed Pig Game" and finally may make the Chamber of Commerce become a tool ${ }^{5}$ used by large companies to manipulate the market and negotiate with the government. This is what we do not want to see. At the same time, there are no special laws in China's trade associations, and they are artificially divided into import and export chambers of commerce and industry associations, which is not commensurate with the global market that China will face after joining the WTO. The chambers of commerce cannot, of course, push companies to join them, for the meaning of the

\footnotetext{
${ }^{4}$ For details, please refer to the Industrial Association and Its Development in China written by Yu Hui and his partners, published by Economic Science Press in 2002 and the Development Theory and Practice of Industrial Association that was majorly edited by Zhai Hongxiang and published by Economic Science Press in 2003, etc.

${ }^{5}$ Here, the situation in Notes 3 is fundamentally different. In the case of Note 3, the Boxed Pig Game is naturally generated in the market. Here it means that the relevant settings brought about after the emergence of the chamber of commerce change the nature of the market. The nature of the chamber of commerce is essentially a club of large corporations.
} 
Chamber of Commerce as a voluntary organization of self-organizing and strengthening domestic enterprises will lose by doing so. Therefore, the solution to the above problems fundamentally depends on the improvement of the level of business of the Chamber of Commerce itself.

Second, deal with anti-dumping in the context through the chambers of commerce.

In recent years, the number of international anti-dumping cases has increased from about 100 each year in the late 1980s to about 240 in the 1990s. And the objects of anti-dumping investigations are mainly minorities. China ranks second in the world after the European Union ${ }^{6}$. This situation is closely related to the fact that China has become a global factory due to its low labor cost and industrial hollowing and economic downturns that have occurred in developed countries. However, China's import and export companies love to fight alone and even dismantle each other during long-term operations, which is very unfavorable to the international anti-dumping response. The functions of the chambers of commerce are different from those of the government. They are not directly under the WTO rules and can be representatives of members to participate in international trade and dispute resolution, help companies respond to lawsuits and apportion lawyer fees among enterprises. They can also organize anti-dumping warning systems.

Develop international economic and technological cooperation and exchanges so as to improve the level of domestic enterprises.

As the Chambers of Commerce have more industry background and professional technical knowledge than universities and government agencies, they should organize more international economic and technological cooperation and exchanges, establish and develop friendly and cooperative relations with foreign industry organizations, and introduce international relevant industry standards and advanced production technologies to companies at home as well as collecting information, establishing publications, guiding and assisting member companies, organizing business training, improving the professional quality and management of member companies, organizing national or regional commodity trading, product exhibition, technology transferring and other activities.

The most important role that the chamber of commerce needs to strengthen is to build a platform of industry-university-research.

(1)While introducing international standards to the industry, the Chamber of Commerce should also participate in formulating and revising various standards for the industry that suit China's national conditions through cooperation with research institutes such as the China National Institute of Standardization. Only in this way can the Chamber of Commerce finally emerge from being controlled by people in the international market. ${ }^{7}$ On this point, we can get some inspiration from the negative teaching materials in the UK. "(British) small industry is growing up on its own. Each railway company...orders equipment according to its own design. In World War II, there were 70 different types of power stations, 50 kinds of power supply systems, and 24 kinds of voltage across the country. There were 122 types of channel iron and angle iron in Britain, while there were only 34 types in Germany. In the field of agricultural machinery, the lack of standardization in the business has made the majority of

\footnotetext{
${ }^{6}$ The relevant data were quoted from New Trends in International Anti-dumping written by Lv Gang, Yang Zhe and Zhang Xiaoji. Please refer to the China's Development Research-Selected Research Report of the State Council Development Research Center published in 2003.

7 In the book "The Age of Modules: The Essence of New Industrial Structure" (Shanghai Far East Press, 2003), edited by Aoki Masaaki, it is clearly reflected that the key to the success of the Silicon Valley model and the defeat of Japanese companies is that an enterprise must control core technologies and standards, become a "designer" and grasp the industry's "road map". Otherwise it will become a module provider, offering others money in research to earn the rest of the profits. Of course, the saddest thing is that you want to be a module provider, but that is not the scope of this article.
} 
market share in the world's iron and plow trade flow to companies in Germany, the United States, and Canada." 8

(2) Historically, we can also understand that the reason why the British economy gradually lags behind other developed countries is largely because of the backwardness of British vocational education during the Second Industrial Revolution, which failed to provide chemical knowledge to laborers and managers. And the rapid progress of German industry mainly results from its handicraft traditions and outstanding handicraft school education. The long-established annual wage system and long-term employment of Japanese companies also mainly result from the shortage of skilled workers in Japanese domestic industry, especially in heavy industry during the two world wars. The complementary relationship between good industrial enterprises and vocational schools can be traced back to Philadelphia textile industry the 19th century.

Since China's reform and opening up, China has consciously taken use of the advantages of labor resources, which has contributed to the employment of a large number of workers. China has gradually become a major processing and manufacturing country in the world. However, with the development of economy and the deepening of technology in various industries, there is a wide gap between the supply and demand of talents in the labor market. That is, unskilled labor is unemployed while skilled labor is in short supply. Some foreign-funded enterprises try to prevent technology backbone workers from going into another company ${ }^{9}$ after the Spring Festival through paying wages before the Spring Festival. It is imminent to strengthen the training of skilled laborers. Only by completing this crucial step can our development truly be sustainable.

At present, high-degree education has become very uneconomical for many low-income families. It can be predicted that the demand for secondary vocational and technical education will increase substantially. And the government vigorously promotes the development of vocational education. On the one hand, due to the fact that the current size of individual enterprises is too small to undertake institutional exchanges with vocational schools, we should promote vocational schools through the platform of chambers of commerce. Establishing stable links with relevant industry enterprises, perfecting the practice system for trainees in vocational schools, and the qualification system for employment, together with the promotion of the implementation of labor laws, can fundamentally regulate the employment conditions of workers in China.

\section{Conclusion}

Apart from the chambers of commerce discussed above, the perfection of China's market economic system also depends on the establishment of other multi-aid mechanisms, such as credit rating systems, urban communities, rural grass-roots organizations, agricultural industrialization organizations, etc.

\section{References}

[1] Game Theory that was written by Drew Fudengberg (USA) and Jean Tirole, published by China Renmin University Press in 2001.

[2] China Development Research - Research report of the Development Research Center of the State Council that was published in 2003 and by China Development Press.

[3] Module Age: The Essence of New Industrial Structure that was majorly edited by Aoki Masahiro and published by Shanghai Far East Press in 2003.

\footnotetext{
${ }^{8}$ Please refer to Chapter 8 of Goldenberg's World Economic Hegemony 1500-1990, translated by Gao Zugui, published by Commercial Press in 2003.

${ }^{9}$ Please see Chen Huai's Blue Collar's Employment: A Topic That Cannot Be Ignored from China Development Research - Selected Research Report of Development Research Center of the State Council published in 2003.
} 
[4] Chapter 8 of Goldenberg's World Economic Hegemony 1500-1990, translated by Gao Zugui, published by Commercial Press in 2003.

[5] Comparative Institutional Analysis that was translated by Zhou Lian and published by Shanghai Far East Press in 2001.

[6] Development Theory and Practice of Industrial Association that was majorly edited by Zhai Hongxiang and published by Economic Science Press in 2003. 